\title{
Nutritional Treatment of Liver Cirrhosis by Branched-Chain Amino Acid-Enriched Nutrient Mixture
}

\author{
Misako OKITA, ${ }^{1}$ Akiharu WATANABE, ${ }^{2}$ and Hideo NAGASHIMA ${ }^{2}$ \\ ${ }^{1}$ Okayama Prefectural Junior College, Okayama 700, Japan \\ ${ }^{2}$ The First Department of Internal Medicine, Okayama University \\ Medical School, Okayama 700, Japan
}

(Received July 30, 1984)

\begin{abstract}
Summary The effects of branched-chain amino acid (BCAA)-enriched nutrient mixture (nutrient-mixture) on the nitrogen metabolism and nutritional state were clinically investigated in 10 patients with liver cirrhosis. Nutrient-mixture-supplemented diet was prepared by adding $150 \mathrm{~g}$ nutrient-mixture daily to low-protein diet, and comparisons were made with a regular diet (control diet). Each diet supplied 2,100 kcal energy and $80 \mathrm{~g}$ protein per day. Patients were given control diet for 2 weeks and thereafter treated successively with nutrient-mixture-supplemented and control diet each for 2 weeks. Nitrogen balance improvement and positive balance were observed during the feeding of nutrient-mixture-supplemented diet. The composition of nitrogen compounds in urine and the fecal nitrogen excretion did not alter during the test period. Plasma aromatic amino acid (AAA) concentrations decreased and BCAA/AAA molar ratios increased significantly during the 1 st and 2 nd week of nutrientmixture-supplemented diet administration. Plasma methionine concentration also decreased in the 1st week. Plasma pre-albumin levels rose significantly during the 1 st and 2 nd week of nutrient-mixturesupplemented diet administration, and the number connection test improved significantly following the supplemented diet. These results suggest that the use of nutrient-mixture in the nutritional treatment of liver cirrhosis had no deleterious effects on nitrogen metabolism and is useful for the improvement of plasma amino acid imbalance and protein-energy malnutrition.
\end{abstract}

Key Words nutritional treatment, liver cirrhosis, branched-chain amino acid, aromatic amino acid, nitrogen balance, pre-albumin

Nutritional treatment is important for the maintenance of the wellcompensated stage and for long-term survival in cirrhotic patients. A diet high in energy and protein is prescribed ordinarily for the purpose of improving the

${ }^{1}$ 沖田美佐子, ${ }^{2}$ 渡辺明治, 長島秀夫 
protein-energy malnutrition frequently observed in decompensated cirrhotics. An abnormal profile of plasma amino acids, low levels of branched-chain amino acids (BCAA: valine, leucine and isoleucine) and high levels of aromatic amino acids (AAA: phenylalanine and tyrosine), free tryptophan and methionine have been reported in advanced cirrhosis of the liver $(1,2)$. A plasma amino acid imbalance, low serum albumin and elevated blood ammonia levels indicate impaired metabolism of nitrogen and protein. Correction of decreased plasma BCAA levels by BCAA supplementation of the diet resulted in improvement of protein synthesis in cirrhotic liver $(3,4)$. Normalization of the plasma amino acid imbalance also prevents hepatic encephalopathy (5).

BCAA-enriched nutrient mixture (nutrient-mixture) is a specially prepared nutritional product for patients with severe liver disease such as fulminant hepatitis and liver cirrhosis, which contains high levels of BCAA and diminished AAA, free tryptophan and methionine. To evaluate the nutritional and clinical efficacy of the nutrient-mixture, a diet supplemented with the nutrient-mixture was tested in comparison with a regular diet served for cirrhotic patients.

\section{MATERIALS AND METHODS}

Subjects. The patients, nine male and one female, were admitted to Okayama University Hospital and were tested in this study (Table 1). The diagnosis of liver cirrhosis was based on peritoneoscopic and histologic observations of the liver. Seven patients had a drinking history (average dose of ethanol $103 \mathrm{~g}$ for 21 years) and two were positive for hepatitis B surface antigen (HBsAg). Patients 4 and 5 had a history of hepatic encephalopathy ( 3 and 5 months before this study). Three patients (Patients 4,5 and 6$)$ received lactulose $(60 \mathrm{ml} /$ day) before, during and after the test period.

Diets. The contents of nutrient and amino acid in SF-1008C (Otsuka Pharmaceutical Co., Ltd., Tokyo), a soft powder nutrient-mixture, are shown in Table 2. It contains $13.0 \mathrm{~g}$ peptide, $13.0 \mathrm{~g}$ free amino acid and $1.0 \mathrm{~g}$ casein; increased BCAA and reduced AAA levels make a high BCAA/AAA molar ratio (38.2). Two kinds of diet ( $80 \mathrm{~g}$ protein and $2,100 \mathrm{kcal}$ energy per day), control and nutrient-mixture-supplemented diet, were prepared. The control diet is one used for chronic liver disease ( $80 \mathrm{~g}$ protein and $2,100 \mathrm{kcal}$ energy per day). Nutrient-mixturesupplemented diet was prepared by supplementing $150 \mathrm{~g}$ nutrient-mixture daily to low-protein diet ( $40 \mathrm{~g}$ protein and $1,500 \mathrm{kcal}$ energy). Fifty g nutrient-mixture was dissolved in $175 \mathrm{ml}$ of lukewarm water and served to the patients as a drink after each meal. During the first 2 week of the study, the control diet was served and basal data were collected. Thereafter, the patients were treated with nutrient-mixturesupplemented diet for the following 2 weeks and then the control diet again for a further 2 weeks (Fig. 1). Food intake was determined during the test period and amounts of various nutrients ingested were calculated according to the Japanese Food Tables (6). Nitrogen intake was calculated using a nitrogen conversion factor 


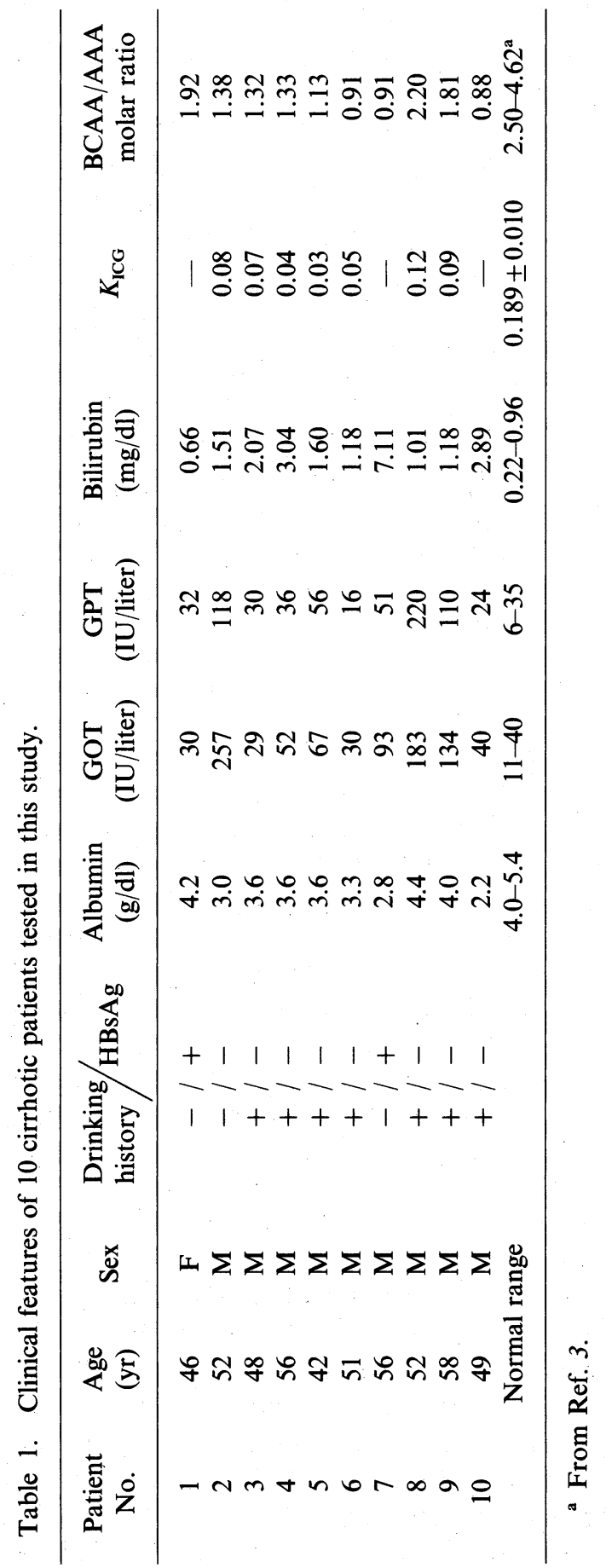

Vol. 31, No. 3, 1985 
Table 2. Nutrient and amino acid composition of the nutrient-mixture.

\begin{tabular}{|c|c|c|c|c|c|}
\hline Protein & & $\begin{array}{c}(/ / 100 \mathrm{~g}) \\
\text { Vitamins }\end{array}$ & & Electro & lytes \\
\hline Peptide & 13.0 & A & $932 \mathrm{IU}$ & $\mathrm{Na}$ & $97.4 \mathrm{mg}$ \\
\hline Amino acid & 13.0 & $\mathrm{D}$ & $93.2 \mathrm{IU}$ & K & $353.0 \mathrm{mg}$ \\
\hline Casein & 1.0 & Thiamine & $199 \mu \mathrm{g}$ & $\mathrm{Ca}$ & $116.6 \mathrm{mg}$ \\
\hline Carbohydrate (g) & & Riboflavin & $310 \mu \mathrm{g}$ & $\mathrm{Mg}$ & $40.4 \mathrm{mg}$ \\
\hline Dextrin & 62.1 & Niacin & $3.05 \mathrm{mg}$ & $\mathrm{Cl}$ & $437.9 \mathrm{mg}$ \\
\hline Lipid & & Pyridoxine & $403 \mu \mathrm{g}$ & $P$ & $167.5 \mathrm{mg}$ \\
\hline \multirow{2}{*}{ Rice oil } & 7.0 & Pantothenic acid & $2.18 \mathrm{mg}$ & $\mathrm{Fe}$ & $2.63 \mathrm{mg}$ \\
\hline & & Ascorbic acid & $12.2 \mathrm{mg}$ & $\mathrm{Zn}$ & $1.71 \mathrm{mg}$ \\
\hline Amino acids (g) & & Biotin & $50 \mu \mathrm{g}$ & $\mathrm{Mn}$ & $0.37 \mathrm{mg}$ \\
\hline Isoleucine & 4.10 & Folic acid & $0.1 \mathrm{mg}$ & $\mathrm{Cu}$ & $262 \mu \mathrm{g}$ \\
\hline Leucine & 4.56 & Cyanocobalamin & $1 \mu \mathrm{g}$ & I & $19.1 \mu \mathrm{g}$ \\
\hline Valine & 3.64 & Choline & $10.1 \mathrm{mg}$ & & \\
\hline Methionine & 0.16 & DL- $\alpha$-Tocopherol & $18.6 \mathrm{IU}$ & Energy & $419 \mathrm{kcal}$ \\
\hline Phenylalanine & 0.31 & acetate & & & \\
\hline Tyrosine & 0.12 & Phytonadione & $11 \mu \mathrm{g}$ & & \\
\hline Tryptophan & 0.16 & & & & \\
\hline Other amino acids & 13.95 & & & & \\
\hline BCAA $/($ Phe + Tyr $) \mathrm{m}$ & olar rat & & & & \\
\hline
\end{tabular}

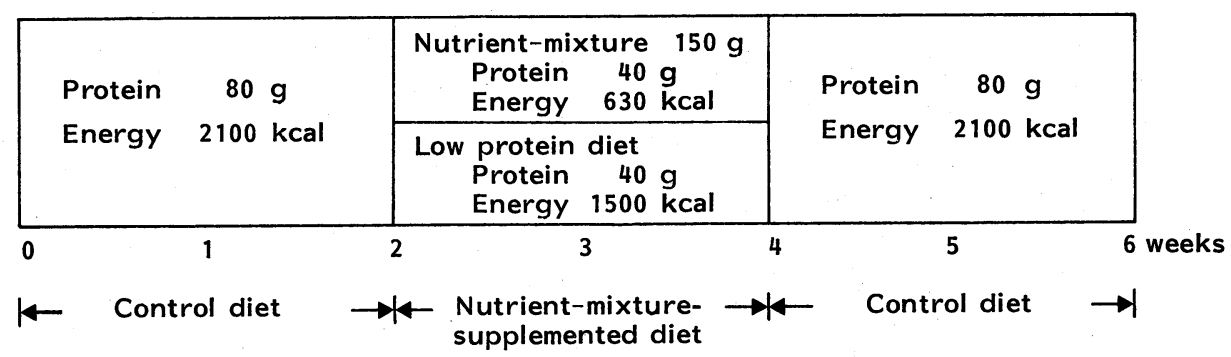

Fig. 1. Feeding schedule of nutrient-mixture-supplemented diet in cirrhotic patients.

of 6.25 .

Analytical methods. Clinical and laboratory tests were performed at the end of each week. After an overnight fast, an aliquot of venous blood was obtained for analyses of blood ammonia, plasma amino acid and other clinical tests. Plasma amino acid concentrations were determined by using a Hitachi amino acid analyzer (Type 835) (Tokyo). Blood ammonia was measured spectrocolorimetrically using a kit (Wako Pure Chem. Industries, Co., Ltd., Tokyo), and pre-albumin was assayed by the immunodiffusion method. Urine and feces were collected over 2 successive days. Urine was collected in a bottle acidified with $6 \mathrm{~N} \mathrm{HCl}$ and analyzed for total 
nitrogen, urea, creatinine, creatine, uric acid, $\alpha$-amino nitrogen and ammonia. Feces were homogenized immediately after they were collected and frozen until analyzed. Total nitrogen contents in urine and feces were analyzed by the micro Kjeldahl method. Statistical significance was determined by Student's $t$-test or Wilcoxon's sign rank test.

\section{RESULTS}

Amounts of energy and protein ingested were significantly high during nutrient-mixture-supplemented diet administration as compared to the control diet (Table 3). The effect of the nutrient-mixture-supplemented diet on plasma amino acid concentrations is summarized in Table 4 . In the basal analyses made during administration of control diet, diminished levels of BCAA ( 8 out of 10 patients) and increased levels of AAA and methionine (9 out of 10) were observed. High levels of glutamic acid, ornithine and 3-methylhistidine and low levels of cystine were also recognized. The nutrient-mixture-supplemented diet resulted in a decrease of AAA and methionine concentrations (Fig. 2). The BCAA/AAA molar ratios were elevated, though a significant rise of BCAA levels was not observed even following nutrient-mixture-supplemented diet (Fig. 3). The elevated BCAA/AAA levels were reduced to basal level again after switching to the control diet. Glycine and hydroxyproline were increased following initiation of the administration of the nutrient-mixture-supplemented diet.

The amount of ingested nitrogen was increased significantly in patients on the nutrient-mixture-supplemented diet. However, urinary nitrogen excretion did not show any significant changes during the test period (Fig. 4). The fecal nitrogen also

Table 3. Average daily intake of energy, protein and amino acid from the diets.

\begin{tabular}{lccc}
\hline $\begin{array}{c}\text { Nutrient and } \\
\text { amino acid/day }\end{array}$ & $\begin{array}{c}\text { Control diet } \\
\text { (Before) }\end{array}$ & $\begin{array}{c}\text { Nutrient-mixture- } \\
\text { supplemented diet }\end{array}$ & $\begin{array}{c}\text { Control diet } \\
\text { (After) }\end{array}$ \\
\hline Energy (kcal) & $1,621 \pm 243$ & $1,932 \pm 269^{*}$ & $1,604 \pm 280$ \\
Protein $\quad(\mathrm{g})$ & $74.3 \pm 7.4$ & $85.1 \pm 6.6^{*}$ & $73.2 \pm 9.2$ \\
Amino acid (mmol) & & & \\
$\quad$ Valine & $36.9 \pm 3.1$ & $68.6 \pm 3.1^{*}$ & $36.7 \pm 6.1$ \\
Leucine & $46.2 \pm 4.5$ & $79.0 \pm 4.3^{*}$ & $45.8 \pm 7.6$ \\
Isoleucine & $28.4 \pm 3.1$ & $63.6 \pm 2.5^{*}$ & $28.1 \pm 4.8$ \\
Phenylalanine & $20.6 \pm 1.9$ & $14.8 \pm 1.9^{\S}$ & $20.4 \pm 3.1$ \\
Tyrosine & $17.0 \pm 1.8$ & $11.3 \pm 1.0^{\S}$ & $16.9 \pm 2.6$ \\
Methionine & $10.8 \pm 1.3$ & $8.5 \pm 1.5^{\S}$ & $11.1 \pm 2.1$ \\
BCAA/AAA molar ratio & $2.97 \pm 0.06$ & $8.13 \pm 0.48$ & $2.95 \pm 0.07$ \\
\hline
\end{tabular}

Data are expressed as mean \pm SD $(n=10)$. Statistical significance was determined by Student's $t$-test. ${ }^{*} p<0.005$, significantly high levels compared with control diet. ${ }^{\S} p<0.005$, significantly low levels compared with control diet. 


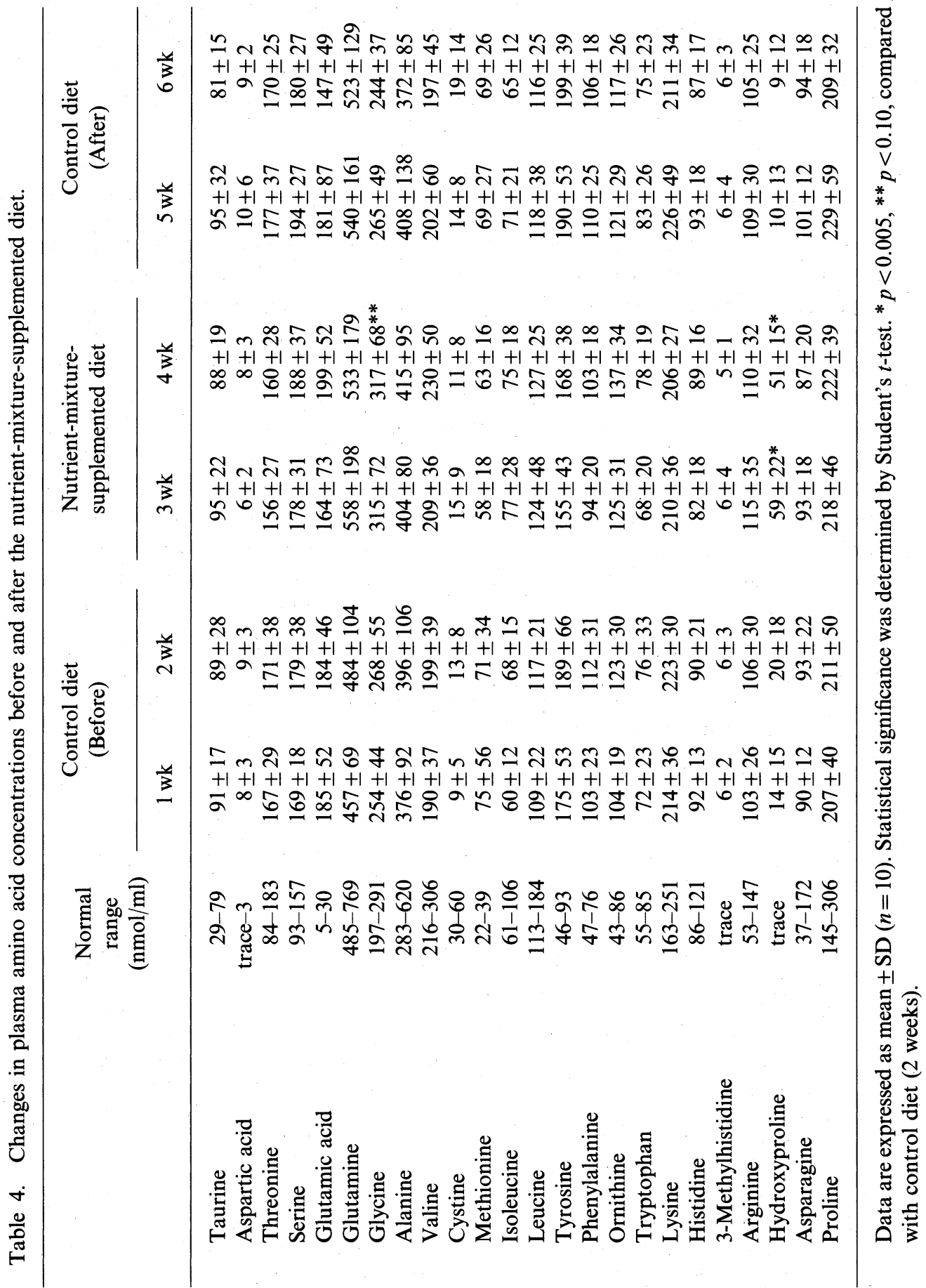




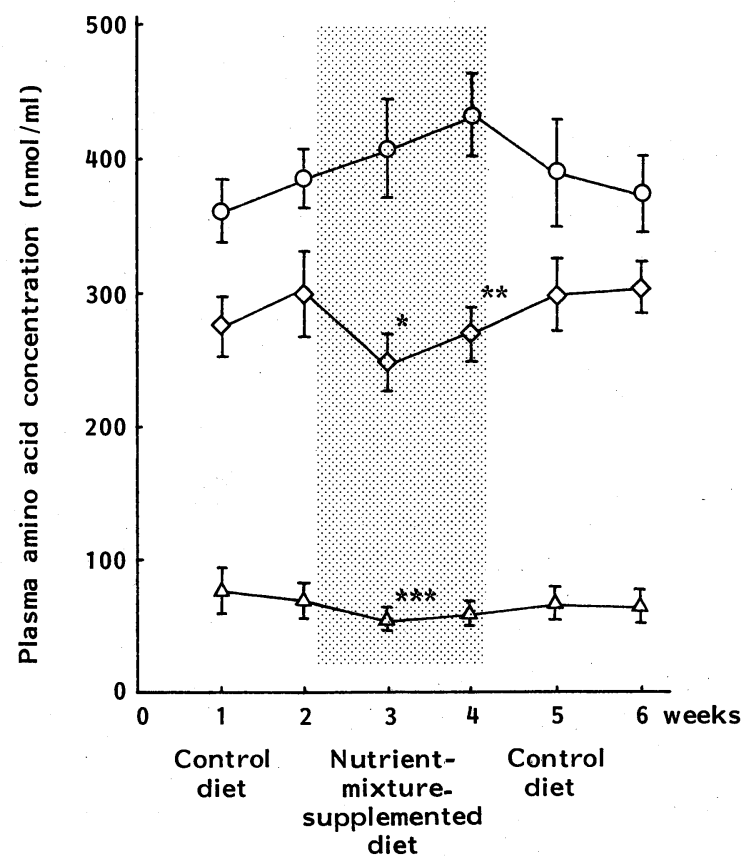

Fig. 2. Changes in plasma BCAA $(O)$, AAA $(\diamond)$ and methionine $(\triangle)$ concentrations (mean \pm SEM, $n=10$ ). Shadow indicates the test period of nutrient-mixturesupplemented diet. Statistical significance was determined by Wilcoxon's sign rank test. ${ }^{*} p<0.005,{ }^{* *} p<0.01,{ }^{* * *} p<0.025$, compared with the levels just before the nutrient-mixture-supplemented diet.

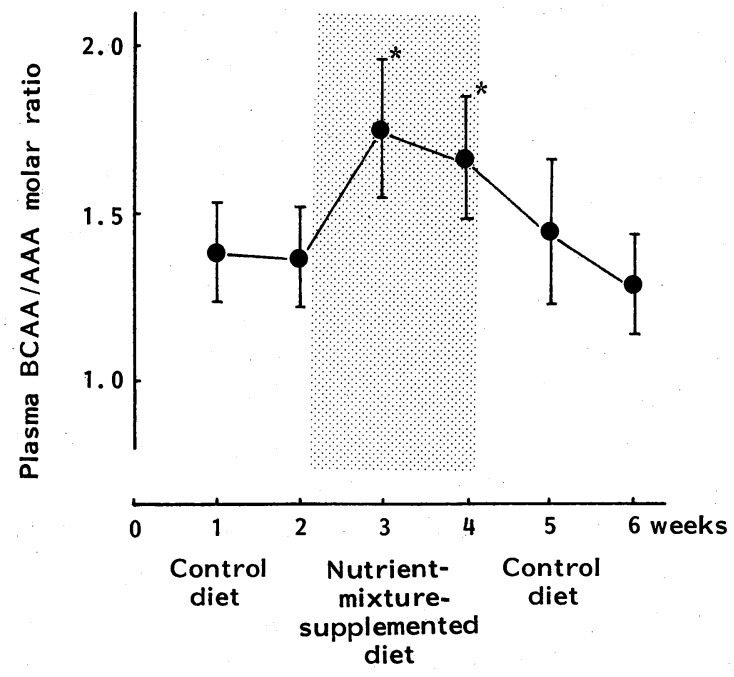

Fig. 3. Change in BCAA/AAA molar ratio (mean $\pm \mathrm{SEM}, n=10$ ). ${ }^{*} p<0.005$, compared with the levels just before the nutrient-mixture-supplemented diet.

Vol. 31, No. 3, 1985 


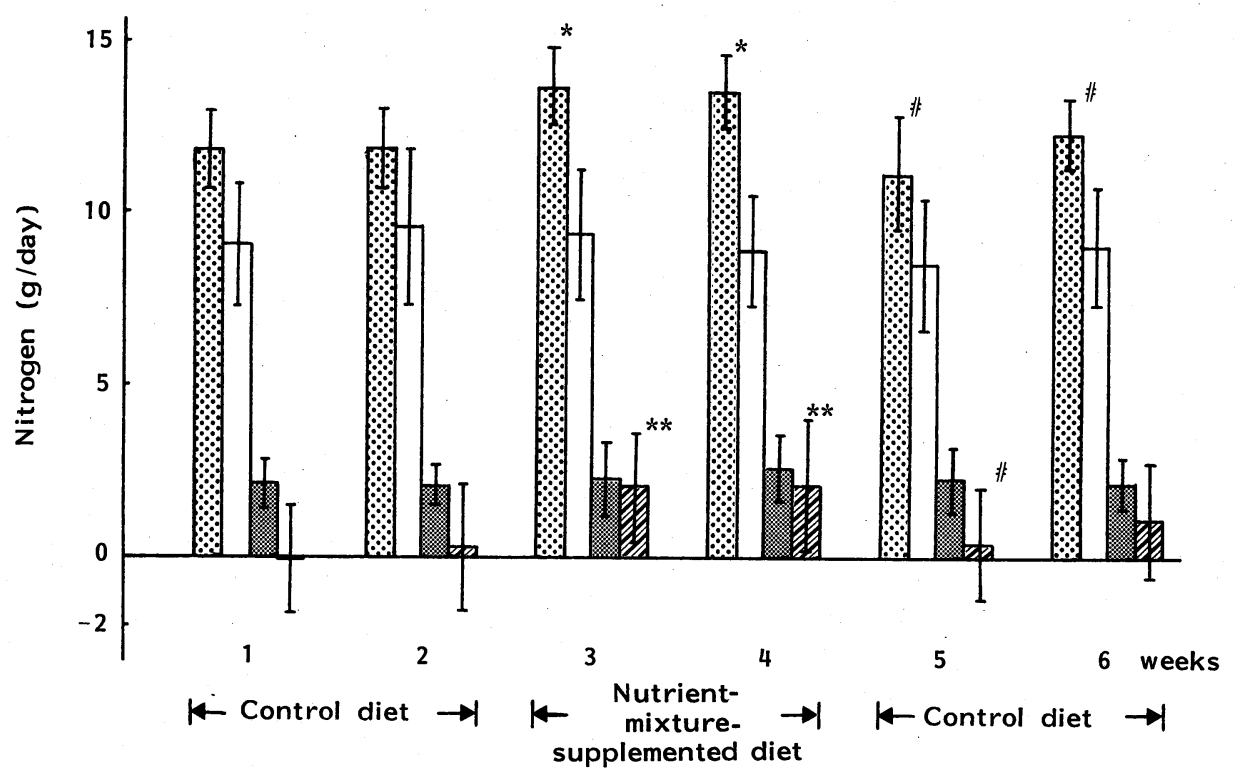

Fig. 4. Daily nitrogen intake ( $\%$ ), urinary nitrogen excretion $(\square)$, fecal nitrogen ( (1) and nitrogen balance ( ) in patients during the test period. Each column represents the mean \pm SD $(n=10)$. Statistical significance was determined by Student's $t$-test. ${ }^{*} p<0.025,{ }^{* *} p<0.05$, compared with the levels just before the nutrient-mixture-supplemented diet. \# $p<0.025$, compared with the levels during the nutrient-mixture-supplemented diet.

was not affected significantly, though it tended to increase $(p<0.10)$ in the 2 nd week of the nutrient-mixture-supplemented diet as compared to the levels observed immediately before initiation of the diet. Nitrogen balance, therefore, was much improved with the nutrient-mixture-supplemented diet and positive nitrogen balances were recognized in all patients. The composition of nitrogen compounds in urine (urea, creatinine, creatine, uric acid, $\alpha$-amino nitrogen and ammonia) remained the same during the test period of nutrient-mixture-supplemented diet administration.

Plasma pre-albumin levels were increased significantly following the supplementation of the nutrient-mixture (Fig. 5). However, there were no significant changes in serum total protein and albumin concentrations. Blood ammonia levels were decreased in 4 out of 6 patients following initiation of the nutrient-mixturesupplemented diet, though the difference was not statistically significant (before, $115 \pm 15 \mu \mathrm{g} / 100 \mathrm{ml}$; during, $91 \pm 26$; 1 week after, $97 \pm 34)$. BUN and plasma $\alpha-$ amino nitrogen concentrations and other liver function tests (bilirubin level, GOT and GPT activities and prothrombin time) were not altered during the test period. The number connection test (normal value in 40-59-year-old healthy controls, $n=20: 30.8 \pm 7.5 \mathrm{sec}$ ) was significantly improved following the nutrient-mixture- 


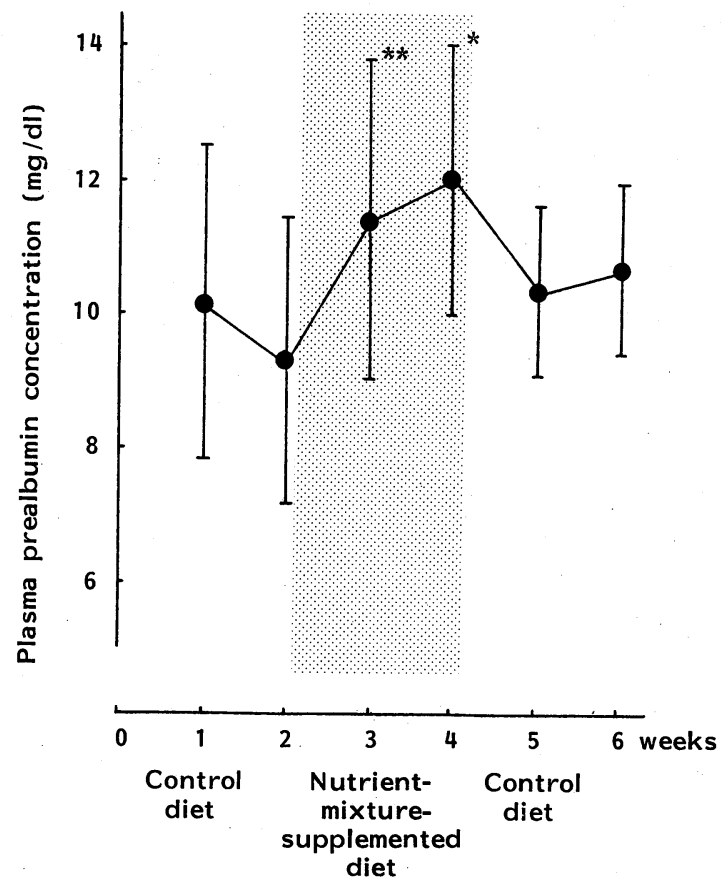

Fig. 5. Change in plasma pre-albumin concentration (mean \pm SEM, $n=10)$. Statistical significance was determined by Wilcoxon's sign rank test. ${ }^{*} p<0.005,{ }^{* *} p<0.025$, compared with the level just before the nutrient-mixture-supplemented diet.

supplemented diet (Fig. 6).

\section{DISCUSSION}

Cirrhotic patients were given a high-protein diet (range $70-90 \mathrm{~g}$ protein/day) prior to the initiation of this study, no clinical encephalopathy being observed in any patient. Two diets, control and nutrient-mixture-supplemented diet, each containing $80 \mathrm{~g}$ protein, were well tolerated in all the patients. Nutrient-mixture drink was easily ingested in all the patients, and thus amounts of ingested energy and protein were significantly large during administration of the nutrient-mixturesupplemented diet compared to that of the control diet.

Compensated cirrhotic patients tested in this study showed diminished levels of BCAA and elevated levels of AAA and methionine as previously reported $(1,2)$. The nutrient-mixture-supplemented diet was expected to be effective for normalizing the abnormal plasma amino acid profile in these patients. Plasma AAA levels were significantly decreased and the BCAA/AAA molar ratio increased significantly upon the initiation of this special diet, although increased BCAA levels were not significant. In our previous study observing diurnal variation of plasma amino acid 


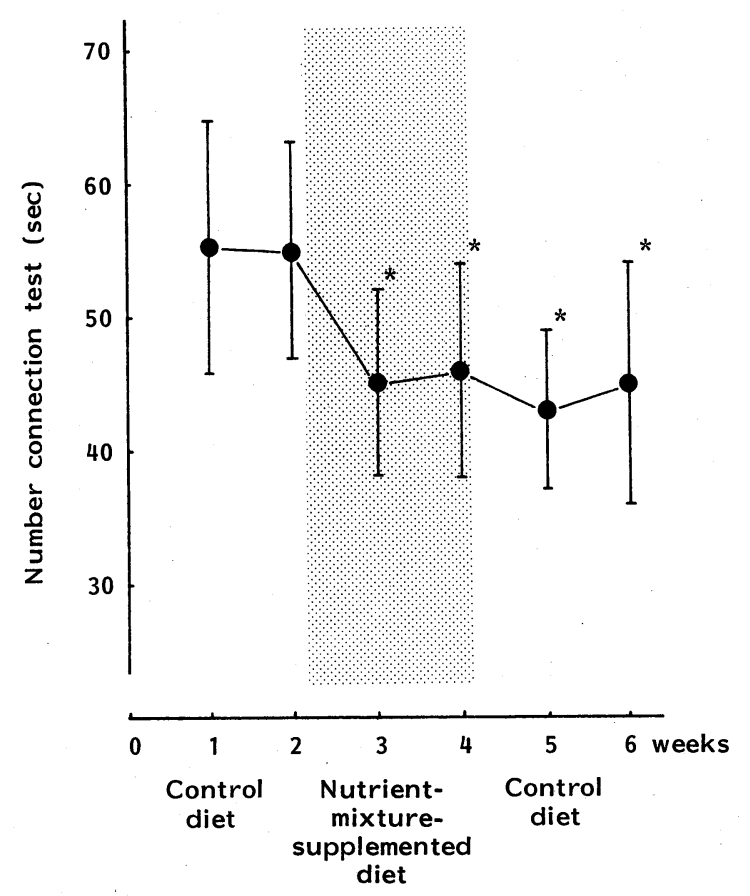

Fig. 6. Effect of the nutrient-mixture-supplemented diet on number connection test (mean \pm SEM, $n=10$ ). Statistical significance was determined by Wilcoxon's sign rank test. ${ }^{*} p<0.005$, compared with the level just before the nutrient-mixturesupplemented diet.

levels following the intake of the nutrient-mixture-supplemented diet, low plasma BCAA levels in a cirrhotic patient rose to normal during the entire 24-h period (7). In the report of McGhee et al.(8) concerning the effects of Hepatic-Aid, a diet containing reduced $\mathrm{AAA}$ and increased BCAA, on plasma amino acid concentrations, they also observed the elevation of BCAA/AAA molar ratio attained by reduction in tyrosine and phenylalanine rather than by increase of BCAA. When the BCAA-supplemented diet was fed to cirrhotic patients (3), fasting plasma BCAA levels were increased and the BCAA/AAA molar ratios elevated, though AAA levels were not changed. The rise of serum pre-albumin concentration may indicate correction of impaired protein synthesis in the cirrhotic liver, probably due to BCAA supplementation and normalization of the plasma amino acid pattern. BCAA, particularly leucine, has been reported to stimulate protein synthesis and, additionally, to reduce protein catabolism in the muscle and liver (9-11). The early start of BCAA supplementation for correcting plasma amino acid imbalance and protein-energy malnutrition is considered to be important for cirrhotic patients to maintain the well-compensated stage for a longer period. Abnormal elevation of plasma methionine levels in the cirrhotic patients was improved by the nutrient- 
mixture supplementation. Methionine has been implicated in the induction of hepatic encephalopathy (12) and impairment of methionine metabolism was reported in liver cirrhosis $(13,14)$. In patients with cirrhosis, reduction in hepatic tyrosine oxidation capacity has also been reported (15). The elevation of plasma glycine levels with the nutrient-mixture-supplemented diet may be due to the inhibitory effect of branched-chain $\alpha$-keto acids on glycine oxidation (16).

Urinary nitrogen excretion was not increased during administration of the nutrient-mixture-supplemented diet in spite of higher levels of nitrogen intake from the nutrient-mixture-supplemented diet than from the control diet. Urea nitrogen constantly accounted for 77 to $79 \%$ of total urinary nitrogen during the test period. The maximal rate of urea synthesis in cirrhotic patients was $42 \%$ that of normal subjects, and hyperammonemia and hyperaminoacidemia observed at the various levels of dietary protein intake were inversely related to the rate(17). Plasma $\alpha$ amino nitrogen, ammonia or urea nitrogen in our cirrhotic patients, however, was not increased by the nutrient-mixture-supplemented diet. It is not clear whether the BCAA-enriched diet prevents muscle protein catabolism(11) and keeps nitrogen balance positive. Positive nitrogen balance observed during the nutrient-mixturesupplemented diet may contribute to the increase of both nitrogen and energy intakes. It may be useful to cirrhotic patients with protein-energy malnutrition to provide sufficient energy and protein, which is beneficial for improving serum amino acid imbalance and hyperammonemia, and also for maintaining a positive nitrogen balance. Fecal nitrogen excretion was higher than normal $(<2 \mathrm{~g} /$ day $)(18)$. Lactulose was effective for decreasing urea production by increasing the fecal

Table 5. Effect of BCAA or nutrient-mixture-supplemented diet on nitrogen balance and serum pre-albumin and amino acid concentrations in cirrhotic patients.

\begin{tabular}{|c|c|c|c|c|}
\hline & \multicolumn{2}{|c|}{$\begin{array}{l}\text { BCAA-supplemented diet } \\
\text { (Previous study (3)) }\end{array}$} & \multicolumn{2}{|c|}{$\begin{array}{l}\text { Nutrient-mixture- } \\
\text { supplemented diet } \\
\text { (The present study) }\end{array}$} \\
\hline & $1 \mathrm{wk}$ & $2 \mathrm{wk}$ & $1 \mathrm{wk}$ & $2 \mathrm{wk}$ \\
\hline Nitrogen balance & - & - & $\uparrow$ & $\uparrow$ \\
\hline Serum pre-albumin & $\uparrow$ & $\uparrow$ & $\uparrow$ & $\uparrow^{*}$ \\
\hline \multicolumn{5}{|l|}{ Serum amino acid } \\
\hline BCAA & $\uparrow$ & $\uparrow$ & 一 & - \\
\hline AAA & - & - & $\downarrow$ & $\downarrow$ \\
\hline BCAA/AAA molar ratio & $\uparrow$ & $\uparrow$ & $\uparrow$ & $\uparrow$ \\
\hline Methionine & - & - & $\downarrow$ & - \\
\hline
\end{tabular}

The data of BCAA-supplemented diet are reported in our paper(3). $\uparrow, \downarrow$ : significant increase or decrease as compared with the respective values during the control diet. *Significantly high (Mann-Whitney's $U$-test) over the 2-wk values during BCAAsupplemented diet. 
Table 6. Comparison of clinical features in patients treated with two different test diets.

\begin{tabular}{lccc}
\hline & & BCAA-supplemented diet & $\begin{array}{c}\text { Nutrient-mixture- } \\
\text { supplemented diet }\end{array}$ \\
\hline Number of cases & & 11 & 10 \\
Age & (year) & $55 \pm 15$ & $51 \pm 5$ \\
$K_{\text {ICG }}$ & & $0.07 \pm 0.03$ & $0.07 \pm 0.03$ \\
Serum albumin & $(\mathrm{g} / \mathrm{dl})$ & $3.4 \pm 0.6$ & $3.5 \pm 0.7$ \\
Bilirubin & $(\mathrm{mg} / \mathrm{dl})$ & $1.55 \pm 0.96$ & $2.22 \pm 1.88$ \\
GOT & (IU/liter) & $88 \pm 46$ & $91 \pm 77$ \\
GPT & (IU/liter) & $85 \pm 67$ & $69 \pm 63$ \\
Serum BCAA/AAA molar & & \\
ratio & & $1.37 \pm 0.52$ & $1.34 \pm 0.46$ \\
\hline
\end{tabular}

Data are expressed as mean $\pm \mathrm{SD}$.

output of nitrogen(19). However, no difference in fecal nitrogen excretion was recognized in patients both with and without lactulose respectively during the observation.

These results agree with our previous ones (3) obtained from the treatment of cirrhotic patients with BCAA-supplemented diet. However, nitrogen balance and serum pre-albumin concentration were improved much more by nutrient-mixturesupplemented diet than by BCAA-supplemented diet (Table 5). The effects of BCAA- or nutrient-mixture-supplemented diet on serum BCAA and AAA levels were evidently different, although the improvements of the serum BCAA/AAA molar ratio after two tests were similar. No difference was recognized in the clinical feaures of the two groups of patient treated with either BCAA or nutrient-mixture-supplemented diet (Table 6). These different effects of two forms of BCAA supplementation may derive from the fact that nutrient-mixture-supplemented diet provided a larger amount of BCAA and less of AAA and had a higher BCAA/AAA molar ratio than BCAA-supplemented diet. From these results, we conclude that the use of the nutrient-mixture in the nutritional treatment of liver cirrhosis had no deleterious effects on nitrogen metabolism, and is useful for the improvement of plasma amino acid imbalance and protein-energy malnutrition.

\section{REFERENCES}

1) Rosen, H. M., Yoshimura, N., Hodgman, J. M., and Fischer, J. E. (1977): Plasma amino acid patterns in hepatic encephalopathy of differing etiology. Gastroenterology, 72, 483-487.

2) Morgan, M. Y., Marshall, A. W., Milsom, J. P., and Sherlock, S. (1982): Plasma aminoacid patterns in liver disease. Gut, 23, 362-370.

3) Okita, M., Watanabe, A., and Nagashima, H. (1984): A branched-chain amino acidsupplemented diet in the treatment of liver cirrhosis. Curr. Ther. Res., 35, 83-92. 
4) Swart, G. R., Frenkel, M., and van den Berg, J. W. O. (1981): Minimum protein requirements in advanced liver disease: A metabolic ward study of the effects of oral branched chain amino acids, in Metabolism and Clinical Implications of Branched Chain Amino and Ketoacids, ed. by Walser, M., and Williamson, J. R., Elsevier/North Holland, Inc., New York, pp. 427-432.

5) Fischer, J. E., Rosen, H. M., Ebeid, A. M., James, J. H., Keane, J. M., and Soeters, P. B. (1976): The effect of normalization of plasma amino acids on hepatic encephalopathy in man. Surgery, 80, 77-91.

6) The Nutrient Composition of Foods in Japan, 4th ed., Ishiyaku Publishers, Inc., Tokyo(1983).

7) Watanabe, A., Shiota, T., Okita, M., and Nagashima, H. (1983): Effect of a branched chain amino acid-enriched nutritional product on the pathophysiology of the liver and nutritional state of patients with liver cirrhosis. Acta Med. Okayama, 37, 321-333.

8) McGhee, A., Henderson, J. M., Millikan, W. J., Bleier, J. C., Vogel, R., Kassouny, M., and Rudman, D. (1983): Comparison of the effects of Hepatic-Aid and a casein modular diet on encephalopathy, plasma amino acids, and nitrogen balance in cirrhotic patients. Ann. Surg., 197, 288-293.

9) Fulks, R. M., Li, J. B., and Goldberg, A. L. (1975): Effects of insulin, glucose, and amino acids on protein turnover in rat diaphragm. J. Biol. Chem., 250, 290-298.

10) Freund, H., Yoshimura, N., Lunetta, L., and Fischer, J. E. (1978): The role of the branched-chain amino acids in decreasing muscle catabolism in vivo. Surgery, 83, 611-618.

11) Marchesini, G., Zoli, M., Dondi, C., Bianchi, G., Cirulli, M., and Pisi, E. (1982): Anticatabolic effect of branched-chain amino acid enriched solutions in patients with liver cirrhosis. Hepatology, 2, 420-425.

12) Zieve, L., Doizaki, W. M., and Zieve, F. J. (1974): Synergism between mercaptans and ammonia or fatty acids in the production of coma: A possible role for mercaptans in the pathogenesis of hepatic coma. J. Lab. Clin. Med., 83, 16-28.

13) Higashi, T. (1982): Impaired metabolism of methionine in severe liver disease. I. Clinical and pathophysiological significance of elevated serum methionine levels. Gastroenterol. Jpn., 17, 117-124.

14) Horowitz, J. H., Rypins, E. B., Henderson, J. M., Heymsfield, S. B., Moffitt, S. D., Bain, R. P., Chawla, R. K., Bleier, J. C., and Rudman, D. (1981): Evidence for impairment of transsulfuration pathway in cirrhosis. Gastroenterology, 81, 668-675.

15) O’Keefe, S. J. D., Abraham, R., El-Zayadi, A., Marshall, W., Davis, M., and Williams, R. (1981): Increased plasma tyrosine concentrations in patients with cirrhosis and fulminant hepatic failure associated with increased plasma tyrosine flux and reduced hepatic oxidation capacity. Gastroenterology, 81, 1017-1024.

16) O'Brien, W. E. (1978): Inhibition of glycine synthase by branched-chain $\alpha$-keto acids. Arch. Biochem. Biophys., 189, 291-298.

17) Rudman, D., DiFulco, T., Galambos, J. T., Smith, R. B., III, Salam, A. A., and Warren, W. D. (1973): Maximal rates of excretion and synthesis of urea in normal and cirrhotic subjects. J. Clin. Invest., 52, 2241-2249.

18) Isaksson, B. (1980): Urinary nitrogen output as a validity test in dietary surveys. Am. J. Clin. Nutr., 33, 4-5.

19) Weber, F. L. (1979): The effect of lactulose on urea metabolism and nitrogen excretion in cirrhotic patients. Gastroenterology, 77, 518-523. 